J. biosoc. Sci. (1998) 30,63-83

(c) 1998 Cambridge U niversity Press Printed in the U nited K ingdom

\title{
SEXUAL NETWORKS AND THE TRANSMISSION OF HIV IN LONDON
}

\author{
MELISSA PARKER*, HELEN WARD AND SOPHIE DAY \\ D epartment of E pidemiology and P ublic H ealth, Imperial College of Science, T echnology \\ and $M$ edicine, $U$ niversity of $L$ ondon
}

\begin{abstract}
Summary. This paper discusses ways in which empirical research investigating sexual networks can further understanding of the transmission of HIV in L ondon, using information from a 24-month period of participant observation and 53 open-ended, in-depth interviews with eighteen men and one woman who have direct and indirect sexual links with each other. These interviews enabled the identification of a wider sexual network between 154 participants and contacts during the year A ugust 1994-J uly 1995. The linked network data help to identify pathways of transmission between individuals who are HIV + and those who are HIV - , as well as sexual links between 'older' and 'younger' men, and with male prostitutes. There appears to be considerable on-going transmission of HIV in L ondon. The majority of participants reported having had unprotected anal and/or vaginal sex within a variety of relationships. The implications of these findings for policies designed to prevent the transmission of HIV are discussed.
\end{abstract}

\section{Introduction}

In the last 10 years there has been increasing interest in the study of sexual networks and the transmission of HIV. One reason for this is that HIV, in common with other sexually transmitted infections, is not randomly distributed. D ocumenting who has sex with whom will help to clarify current and future patterns of transmission (A nderson, G upta \& N g, 1990; A nderson \& M ay, 1992; G upta, A nderson \& M ay, 1989; M orris, 1994), refine notions of risk and generate information crucial to the design of strategies preventing the future transmission of sexually transmitted diseases (K lovdahl, 1985; $\mathrm{N}$ eagius et al., 1994; Trotter, R othenberg \& Coyle, 1995).

To date, empirical research investigating sexual networks and the transmission of HIV in the W estern world has been limited. It has been undertaken in the U SA (e.g. A uerbach et al., 1984; K lovdahl et al., 1994; Laumann et al., 1989; Laumann, 1994; Service \& Blower, 1995; Woodhouse et al., 1994) and, to a lesser extent, Iceland (H araldsdottir, Gupta \& Anderson, 1992) and the UK (Coxon, 1995). This research

*Present address: D epartment of $\mathrm{H}$ uman Sciences, Brunel U niversity, U xbridge, M iddlesex, U B8 $3 P H, U K$. 
has involved the analysis of egocentric network data and/or been undertaken in an area where the prevalence of HIV is low. M oreover, researchers have elicited information on sexual behaviour through structured and semi-structured interviews and little attention has been given to documenting the outlooks of the study participants. Surprisingly little is known, therefore, about the social context in which sexual partnerships are formed and break down and the ways in which social links influence sexual behaviour.

This paper discusses sexual networks and the transmission of HIV in London. It is based upon research with male participants who have direct and indirect sexual links with each other. It is anticipated that research investigating sexual networks and the transmission of HIV in London will continue and the data presented in this paper should thus be seen as work in progress.

Aims

The overall aim of this paper is to identify the sexual links between those who are $\mathrm{HIV}+$ and those who are HIV - with a view to addressing the following questions. To what extent does any one person's position in a network affect their risk for acquiring and transmitting HIV (over and above the effects of individual risk behaviour)? How does the investigation of sexual mixing among linked individuals increase understanding of the transmission of HIV? What are the implications of the results presented in this paper for the prevention of HIV in London?

\section{M aterial and methods}

\section{Fieldwork}

Fieldwork was undertaken in London, $U K$, at a clinic for sexually transmitted diseases, various public venues and the flats and houses of study participants. L ondon is an important and interesting setting for research investigating sexual networks as the majority of AIDS cases and HIV-1 infections in the UK are thought to occur in this city. It has recently been reported that the Thames regions accounted for $70 \%$ of all AIDS cases reported $(8005$ of 11,494$)$ and $64 \%$ of all HIV -1 infection reports $(16,253$ of 25,276 ) in the UK (PHLS AIDS Centre, 1995).

\section{$M$ ethods}

Two methods have been employed to identify sexual networks in London. First, patients who received a positive diagnosis for gonorrhoea at a clinic for sexually transmitted diseases and/or attended the clinic as a contact of someone who had recently been diagnosed with gonorrhoea were invited to participate in the research. Second, contact with the sexual partners of these patients was subsequently made through snowball sampling. This involved asking participants to contact current and past sexual partners to ask them whether or not they would be willing to participate in the study. They were also asked to contact friends who they felt played a significant part in their social life to see whether or not they would be willing to participate in the research. Interviews with friends were undertaken with a view to acquiring a better understanding of the social world of each participant. These interviews provided an 
additional opportunity to explore the nature and extent of sexual links, however complex, with friends. Once sexual contacts and friends had been interviewed, they were then asked to contact past and present sexual partners and friends with a view to expanding the social and sexual network.

Information elicited from all participants

The following information was elicited from participants: social and demographic information about the participant (including their age, residence, current occupation, current living situation, education); a detailed account of their past and current sexual behaviour (including the total number of sexual contacts they had ever had; the total number of sexual contacts they had had between 1st A ugust 1994 and 31st J uly 1995; the dates of first and last sex with each contact; and the types of sex they had with each contact during this 12-month period); information about their HIV status, past and/or current IV drug use; a history of the number and type of other sexually transmitted infections they had acquired (including gonorrhoea, chlamydia, genital herpes) and, where possible, the year and month the infection was diagnosed.

In addition, sociodemographic and biomedical information was obtained about the sexual contacts mentioned by participants for the period between 1st A ugust 1994 and 31st J uly 1995. This included information about each contact's age, nationality, sexual health, ethnicity, and the number and type of sexual contacts the participant's contacts had had during this 12-month period. Descriptive information about the place and context in which the participant met his/her sexual contacts has also been collected and, wherever possible, the sexual links (if any) that exist between the participant's contacts and the contacts' contacts were documented.

Interviews lasted for 1-4 hours and, where possible, were tape recorded. They either took place at the clinic or the participant's flat/house. Information was elicited by asking open-ended questions rather than following the structured format of a questionnaire. This enabled information about each participant's sexual history to be acquired over similar periods of time as well as encouraging the participant to reflect on issues such as why they have sex with the numbers and types of people they do; why a participant has unprotected sex on one occasion and not another; and how, if at all, their understanding of the risks for acquiring and transmitting HIV infection influence their sexual behaviour.

\section{Confidentiality}

Participants were recruited to the study on the understanding that all the information imparted during an interview would be treated in confidence and would not be relayed to any other participant or health professional. Similarly, information conveyed by other participants would not be relayed back to them, irrespective of the pressures and dilemmas this may present to the researcher.

I dentification of sexual networks

The sexual network discussed in this paper concerns sexual links between participants and their contacts for the year A ugust 1994 to J uly 1995. The identification of this network initially began by investigating the transmission of gonorrhoea. Over 


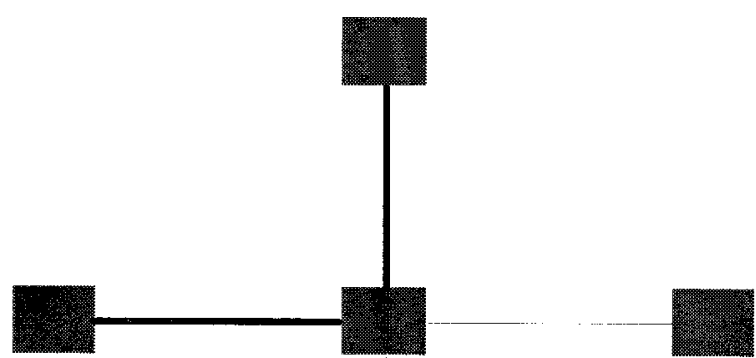

2.2. HIV+

protected anal sex and/or oral sex

unprotected anal sex

Fig. 1. Sexual contacts reported by participant 1 in A ugust 1994.

time, however, it became impossible to track the infection and to identify the network facilitating transmission as it was not possible to secure the necessary participation from those who might have been exposed to gonorrhoea, that is, sexual contacts in the previous 3 months.

H owever, it was possible to secure the participation of several people who had had sex with the index patient over the longer period of 12 months. The identification of this network may be described as follows: an A ustralian 20-year-old man (participant 1) attended a London clinic for sexually transmitted diseases to be treated for gonorrhoea in A ugust 1994. $\mathrm{He}$ is also H IV + and thought he might have acquired this recent episode of gonorrhoea from one of four possible sexual contacts.

Coincidentally, these four sexual contacts were also reported to be HIV + (Fig. 1). The participant was asked to inform all four contacts of his recent infection, to advise them to be screened for gonorrhoea at a clinic for sexually transmitted diseases, and to ask them whether they would be willing to participate in research investigating sexual and social networks. N one of them came to be screened for gonorrhoea at the clinic attended by participant 1 and, so far as is known, they did not attend any other genito-urinary medicine clinic in London to see whether they were infected with gonorrhoea. M oreover, the four contacts refused to contribute to the research. In fact they thought participant 1 was 'mad' for agreeing to be interviewed. 


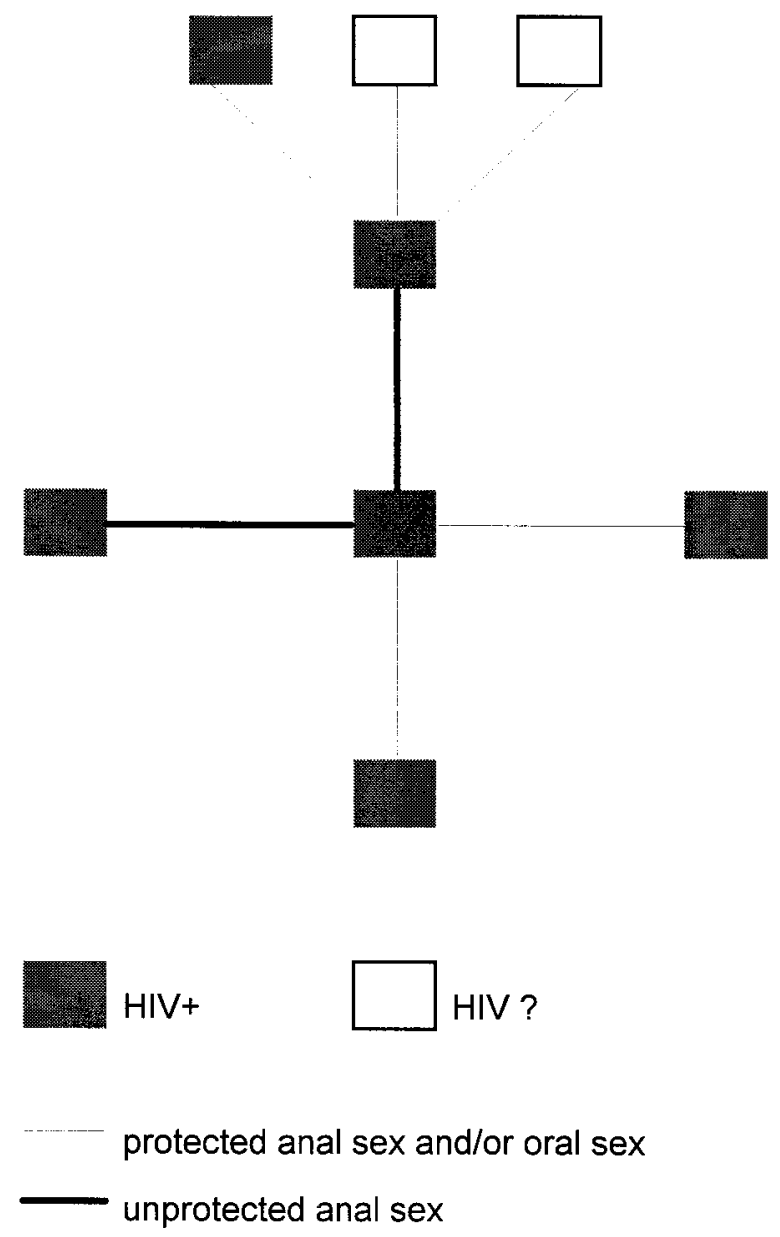

Fig. 2. R eported sexual links and HIV status of two participants between A ugust 1994 and October 1994.

H owever, one of these four contacts subsequently attended the clinic to be treated for gonorrhoea in October 1994. He had probably acquired this infection from a different source and after considerable discussion he agreed to participate in the research investigating sexual networks. During the first interview this participant (participant 2) mentioned that he had had four sexual contacts since 31st J uly 1994 (Fig. 2). He did not say whether he had heard about the study from participant 1 and it is thought that they do not know that they are both contributing to the study.

The first participant agreed to additional interviews and these took place at 2-monthly intervals. This enabled a detailed picture of his sexual links in the years prior to his recent diagnosis for gonorrhoea to be acquired and a record to be kept of his 'new' sexual contacts since the previous interview. By A ugust 1995 he reported having had 33 sexual contacts between 1st A ugust 1994 and 31st July 1995 (Fig. 3). To his knowledge two of these contacts had had sex with each other. 


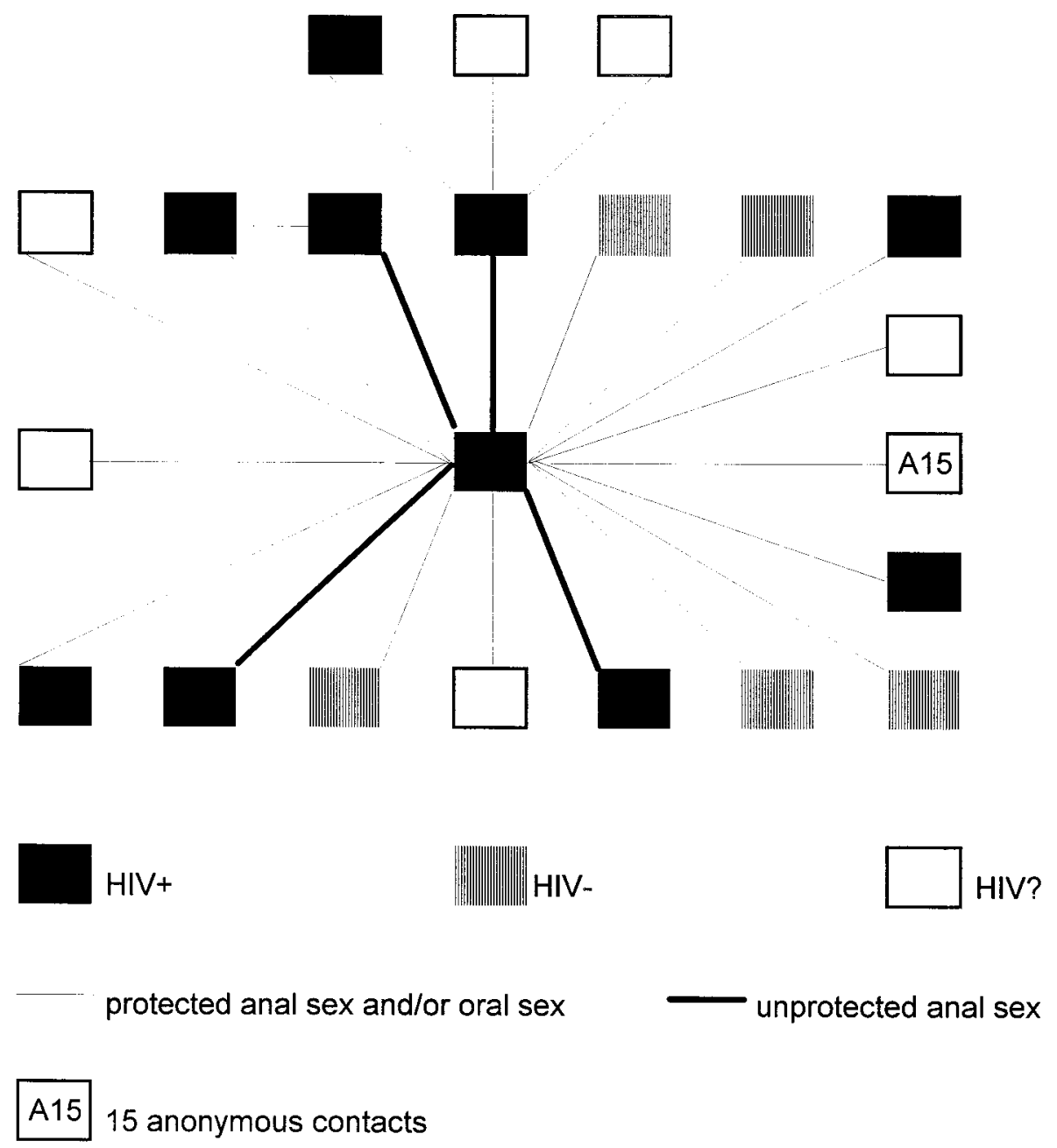

Fig. 3. R eported sexual links and HIV status of two participants between A ugust 1994 and July 1995.

Eight months and four interviews after first meeting this participant he secured the participation of three friends with whom he had had indirect sexual links as well as one current sexual contact. Interviews were undertaken at their flats and the links established are depicted in Fig. 4.

D uring this time, the second participant was interviewed at regular intervals. Eight months and three interviews after the first meeting he secured the participation of his long term sexual partner. The sexual contacts of participant 2's long term sexual partner are also shown in Fig. 4. U nfortunately, it has not been possible to interview participant 2's other contacts as they are all resident overseas.

H owever, it was possible to secure the participation of one of participant 1's sexual contacts through the clinic referral system. This contact is HIV + and attended the 


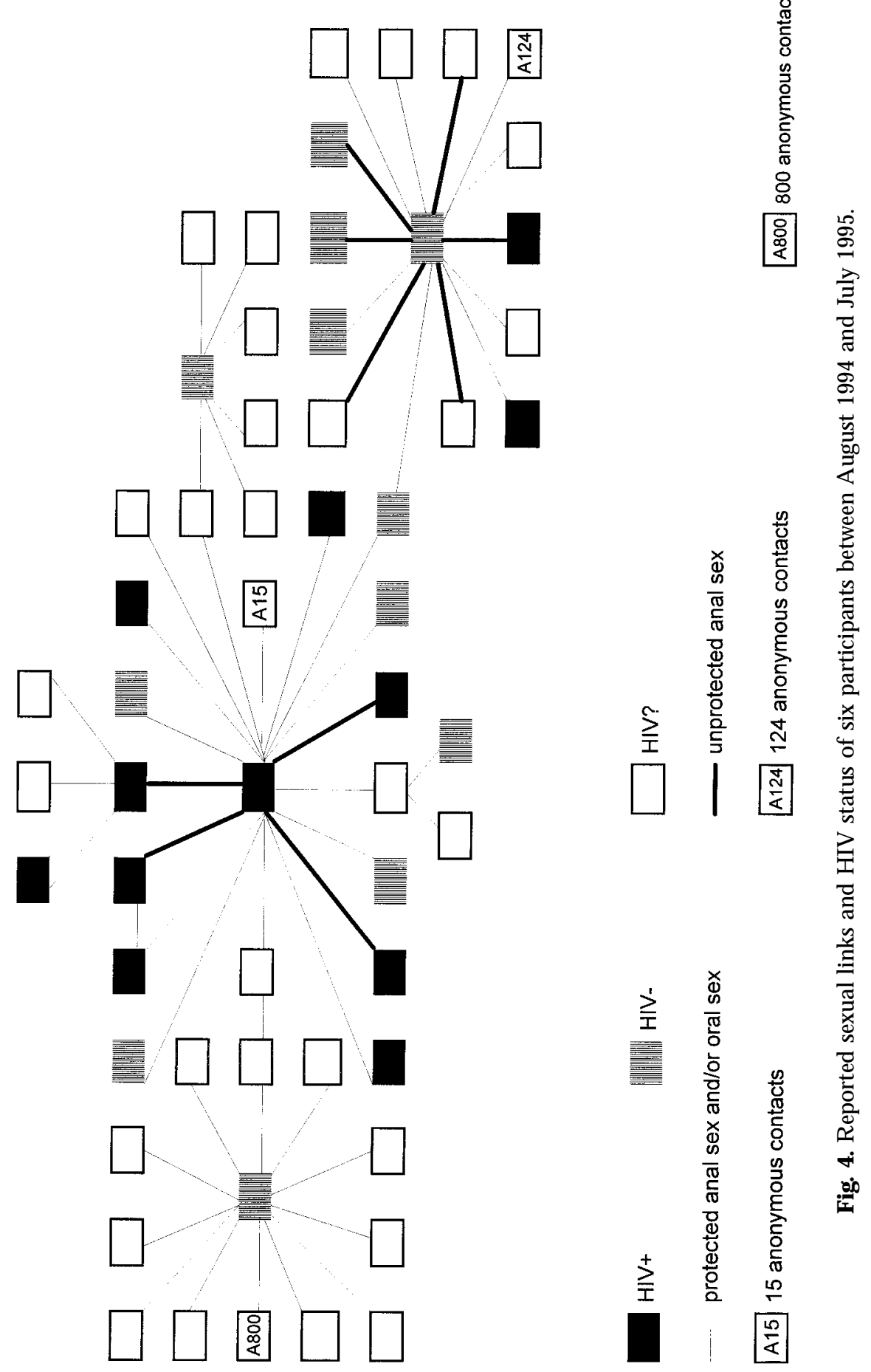


clinic to be treated for gonorrhoea in October 1995. In addition, two out of four of participant 1's friends and contacts persuaded five of their past and current sexual contacts to participate in the study. They, in turn, recruited a further four sexual contacts to the study. D uring the last month of data collection, two out of four of these contacts each recruited a further contact to the study. The sexual links between all nineteen study participants are presented in Fig. 5.

\section{Additional contextual information}

The collection and interpretation of data concerning this network has been influenced by information acquired during interviews with a further 36 men who reported having sex with other men and who attended the clinic to be treated for gonorrhoea. A total of 54 interviews were undertaken with these men between J anuary 1994 and N ovember 1995 and, as far as is known, they do not have any sexual links with each other or with any of the nineteen men reported to be linked to each other.

These interviews did not follow a set format. They were open-ended and unstructured and most of them occurred prior to the development of the network discussed in this paper. They generated an enormous amount of contextual information on the gay scene and lifestyles, and drew attention to the fact that enumerating sexual activity is far from straightforward. The reasons vary and include the fact that the number of sexual contacts any one participant talks about varies according to whether he is asked 'how many partners have you had in the last 12 months?', 'how many contacts have you had in the last 12 months?', and 'how many penetrative contacts have you had in the last 12 months?'. M oreover, a wide range of terms are used by participants to describe different types of sexual relationships. These include 'boyfriend', 'sex friend', 'fuck buddy', 'a cas shag', 'a quickie', 'a bit of a rummage', 'a drunken pick-up' and so on. Different participants attribute different meanings to these terms but it was clear that the distinction made by staff in a clinic setting between 'regular' and 'casual' contacts was not a distinction shared by the majority of participants.

\section{R esults}

By $M$ arch 1996 one woman and eighteen men who were all linked to each other through a variety of complex sexual links had been interviewed. A total of 53 interviews had been undertaken with these nineteen participants, the number of interviews per person ranging from one to ten.

A s a result of these interviews 1378 sexual contacts were mentioned, of which 1261 (91.5\%) were untraceable as they involved either anonymous, one-off sexual encounters in public places (such as saunas, parks, darkrooms, cemeteries and public toilets) or one-off commercial encounters where the prostitute or client concerned did not have information enabling their contact to be traced. Of the remaining 117 traceable contacts, seven were female and 110 male.

D espite the anonymous nature of many of the sexual contacts cited, participants were sometimes able to gauge the age of the contact and occasionally acquired information about their nationality, ethnicity, HIV status, etc. By combining this 


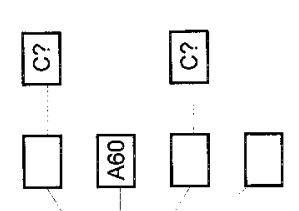

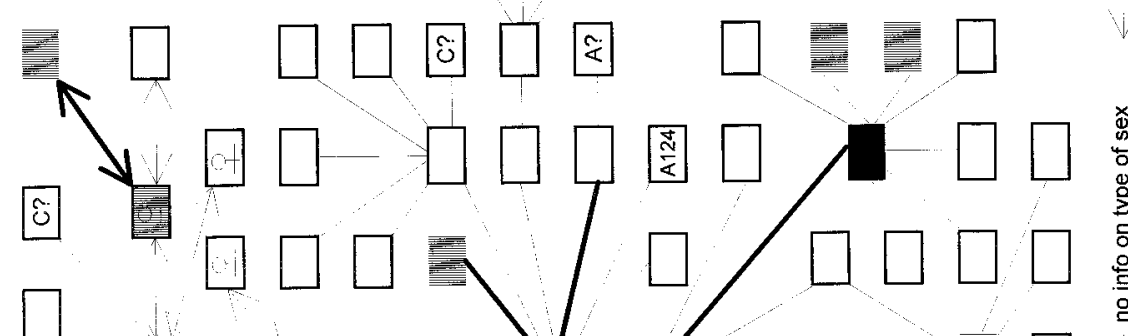

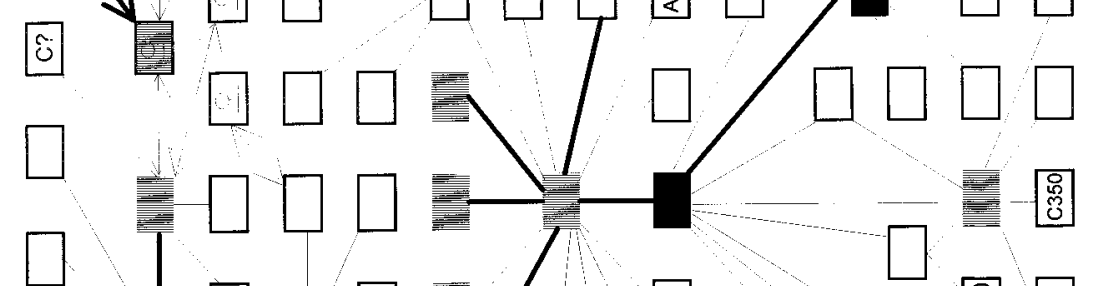

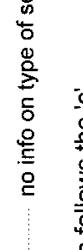

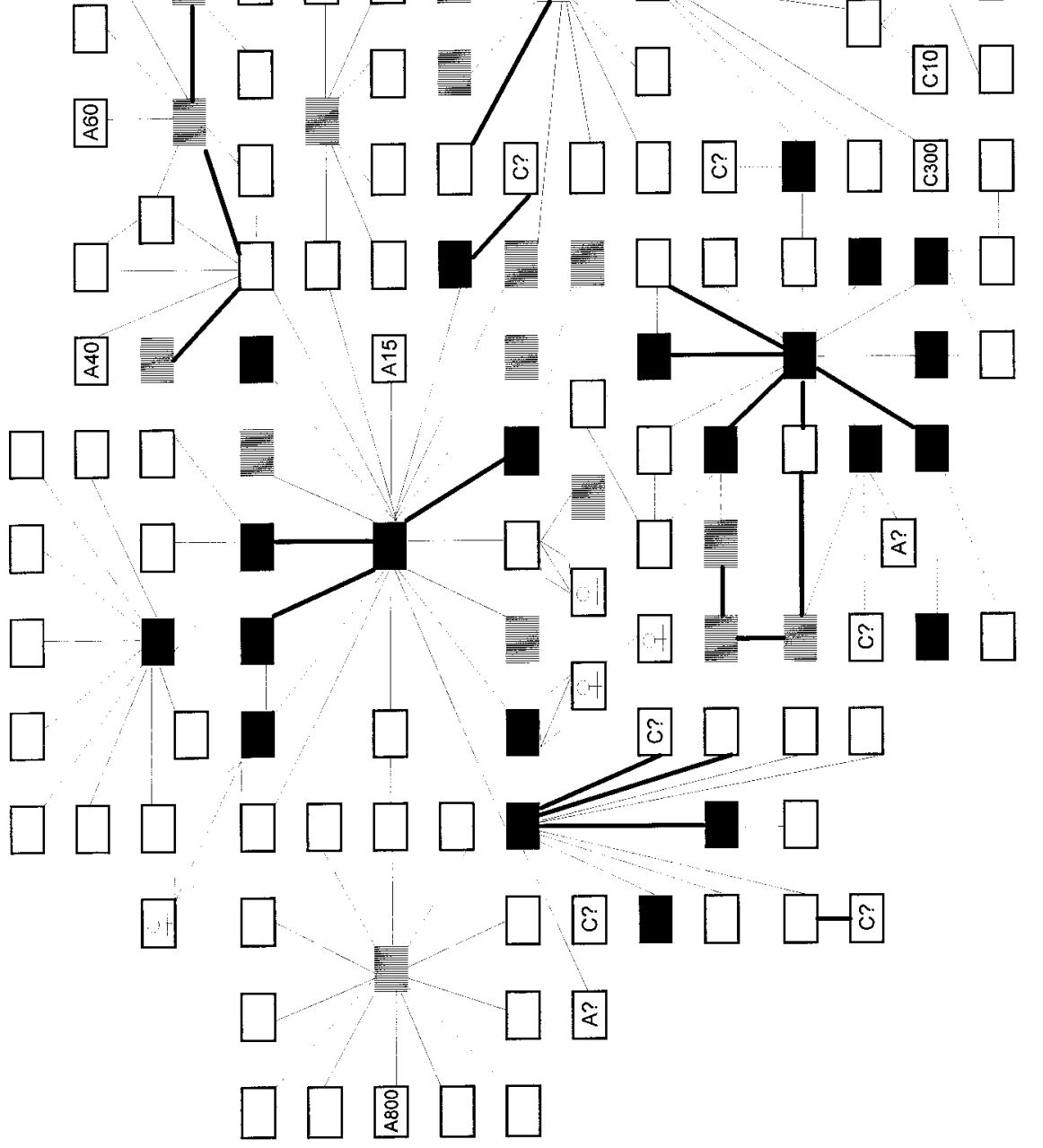

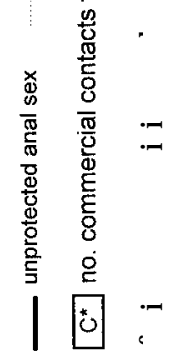

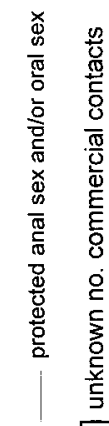

s。

主

$\square$

主

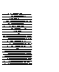

站总 
Table 1. Sexual contacts reported by participants $(n=19)$

\begin{tabular}{|c|c|c|}
\hline $\begin{array}{l}\text { Estimated no. of } \\
\text { sexual contacts }\end{array}$ & 1994-95 & Ever \\
\hline 1 & 0 & 0 \\
\hline 2 & 1 & 0 \\
\hline $3-4$ & 2 & 0 \\
\hline $5-9$ & 2 & 0 \\
\hline $10-50$ & 8 & 3 \\
\hline $51-100$ & 2 & 1 \\
\hline 101-999 & 4 & 7 \\
\hline$>1000$ & 0 & 8 \\
\hline $\begin{array}{l}\text { Total no. of } \\
\text { participants }\end{array}$ & 19 & 19 \\
\hline
\end{tabular}

information with information about other sexual contacts (i.e. where the person is not anonymous but involves sexual contact with someone that they know something about) there is sociodemographic and biomedical information on a total of 154 contacts.

Social, demographic and biomedical information about the participants

A diverse group of people contributed to this research. The participants ranged in age from 19 to 50 years and the average age was 32 years. The majority of participants (thirteen) were British but there was also one participant from Sweden, India and A ustralia respectively. A further three participants had dual nationality, of B ritain/U SA, Britain/N ew Zealand, and F rance/C ameroon respectively.

Occupation and income varied greatly. Two participants were students, three were out of work, five sold sex and/or sold sex in addition to undertaking other commercial activities; and nine received salaries for the work they undertook. Participants' incomes reflected this spectrum of work. R eported incomes ranged from less than $f 215$ to more than $f 2595$ per month; the average monthly income was $f 1080$.

The sexual health and sexual activity of participants may be summarised as follows: seven participants were HIV +, seven were HIV - and five did not know their HIV status. The number of reported contacts for the year A ugust 1994-J uly 1995 ranged from two to an estimated 800 contacts; the distribution of contacts is presented in Table 1.

Sociodemographic, biomedical and behavioural information about the network

Sociodemographic, biomedical and behavioural information elicited from study participants about the wider network of 154 sexual contacts may be summarised as follows: 147 contacts were men and seven were women. These contacts ranged in age from 19 to 53 years and the average age was 30 years. The majority of the participants' sexual contacts (113) were resident in L ondon. A further three contacts were passing through L ondon on holiday or business and 38 sexual contacts were made by four participants overseas. 
The majority of the participants' contacts (87) were B ritish but sexual contact was also made with men from a further 21 countries: nineteen contacts were from U SA and six were from A ustralia. Three contacts were from I reland and Brazil respectively; and a further two were from Greece, Malaysia, Portugal and Spain respectively. Participants also reported having one contact from Bosnia, India, Croatia, Holland, I srael, Italy, L ebanon, M adagascar, South A frica, Sweden and $\mathrm{N}$ ew Zealand; three contacts were reported to have the dual nationalities of A rgentina/Italy, Brazil/Italy, $\mathrm{F}$ rance/Cameroon. Participants did not know the nationality of 32 of their contacts.

Participants acquired relatively little other information about their contacts. $\mathrm{N}$ evertheless, on the basis of available information, it is apparent that their contacts were engaged in a wide range of activity and employment: 60 contacts were reported to be in full or part-time work and their occupations included: solicitor, journalist, university lecturer, priest, merchant banker, greengrocer, air steward, chef, shop assistant, nurse, opera singer, manager of a gay club. A further ten contacts were students, nineteen were either selling sex or selling sex in addition to undertaking other income-generating activities; eleven contacts were out of work. There was no information about 54 of the 154 contacts.

Participants knew much less about the sexual health of their contacts. Thus, 23 men in this network were reported to be HIV +, 23 people were reported to be HIV - and there was no information about the HIV status of a further 108 men (excluding anonymous contacts). Contacts and participants were a maximum of five steps away from reported HIV infection and the majority of those who were HIV - or did not know their status did not realise how close they were to HIV infection.

\section{Transmission of HIV}

Source and duration of infection. N one of the participants in the network who are HIV + thought they had acquired the virus from any of their sexual contacts in the year of data collection. While five of these participants did not have any idea where they had acquired the infection from; two felt able to attribute the source of infection to a particular individual who they had had sex with at least 3 years ago. It is thus not possible to investigate in an empirical way the extent to which an individual's position in this network affected their risk for acquiring HIV infection. However, it is possible to look at mixing patterns within the network and by addressing the question 'who has sex with whom' and 'why' to identify pathways of transmission; and to explore the implications for public health interventions seeking to prevent the transmission of HIV.

A ge mixing and commercial sex. Five participants were 40 or more years old and reported having sex with men between the ages of 20 and 30 years old. The attractions of having younger sexual contacts vary and, in the words of one participant, include the fact that they like their 'vitality, their vividness of life ... and they are just old enough to be interesting about it'.

It is not necessarily easy for 'older' men to have sexual contact with 'younger' men. Indeed, these older men drew attention to a phenomenon confirmed by their younger counterparts: older men are widely perceived as 'old meat'. It can take up to 6 hours to find a contact in public places such as saunas. Thus men in this age group often 
prefer to recruit contacts by paying for sex. There is no shortage of younger men willing to sell sex and many older men have regular commercial contacts that they see on a weekly or monthly basis.

Interviews with men selling sex in this network have identified two potentially important pathways of transmission. First, information about these men, in combination with information imparted about friends and associates who are also selling sex, suggests that an ethnically diverse group of men are selling sex. The men selling sex in this network are from India, A ustralia, U SA and U K. Some of them are trying to fund their way through university and others are trying to raise money while they set up businesses in the UK. Whatever the reason the majority are less than 25 years old, report others, if not themselves, selling unprotected anal sex, and they are also active on the scene. They all described having non-commercial sexual contact with other men of similar ages to themselves. This information suggests that male prostitutes may have acquired HIV from older clients and, in some cases, passed it to non-commercial, similar aged male contacts.

Second, at least ten of the nineteen men in this network who sell sex are HIV + (i.e. those who have either been interviewed or whose status and activity is reported by a friend, or a past or current contact). The prostitutes that have been interviewed all report having a considerable number of clients who have heterosexual sex. Precise figures are difficult to acquire but, without exception, they estimate that $40-50 \%$ of their clients fall into this bracket. This is not to suggest that all sexual contact is 'unsafe' but it is apparent that unprotected anal sex occurs as it is the most lucrative sex to sell. Consequently male prostitutes may be an important bridge between gay and heterosexual populations.

Type of sex and type of partnership. It is often difficult to elicit accurate information about the occurrence and frequency of unprotected anal or vaginal sex, particularly among HIV + men, and especially if they regularly have unprotected anal sex with other men who are either HIV - or do not know their status. These men are under considerable external pressure to behave otherwise as they know others will see such behaviour as unacceptable. M en who are HIV - are also under considerable external pressure to have protected rather than unprotected anal sex unless their partners are HIV - too. In common with men who do not know their status, HIV - men are quick to anticipate criticism for having unprotected anal sex on the grounds that it is 'irresponsible' and 'letting the side down'. N ot surprisingly, therefore, the majority of men in this study were reluctant to talk about the fact that they had had unprotected anal sex at a first or second interview. And on those occasions when they did report having this type of sex they suggested it was an unusual occurrence.

The following example illustrates some of the difficulties of acquiring accurate information about sexual behaviour. Participant 15 is HIV + . He spoke openly about the fact that he regularly has unprotected anal sex with his partner of 7 years' standing, but this piece of information emerged at the end of the second interview when the tape recorder had been switched off. It was also clear that he would not have said anything had it not been for the fact that his partner had had his first HIV test a week before this interview and tested positive. They were both distraught by the diagnosis and he said that neither of them had ever spoken to friends or health professionals about the 
sex they had as it was their 'secret' and he knew people would be critical of him for 'signing his death warrant'.

There is no way of knowing how often an individual has unprotected rather than protected anal sex but it is clear that data monitoring the frequency and occurrence of unprotected anal sex should be interpreted cautiously as there is considerable under-reporting. The tendency to under-report the occurrence of unprotected anal sex is worrying in view of the fact that data collected during this study showed that the majority (ten) of participants had had unprotected anal sex and/or unprotected vaginal sex with one or more people between A ugust 1994 and J uly 1995.

The context in which unprotected anal or vaginal sex occurred varied greatly and, on the basis of this study, it was not possible to associate unprotected sex with a particular type of sexual relationship. U nprotected vaginal sex occurred within the context of a 'one night stand' and a relationship of 3 months' standing. U nprotected anal sex occurred between 'fuck buddies' where the individuals concerned are HIV + and open with each other about their status. It also occurred within the context of long term partnerships and commercial contacts. A mong long term partnerships, two instances were described: participant 8 is HIV - and reported having unprotected anal sex with his boyfriend of 12 months' standing. This boyfriend, participant 9, does not know his H IV status and he is concerned that he may be positive and that he may have passed the infection to paticipant 8. By contrast, participant 11 is HIV + and participant 13 does not know his HIV status. They have been together for 5 years and regularly have unprotected anal sex.

A considerable amount of unprotected anal sex was also reported by participants buying or selling sex. The principal attraction of selling unprotected sex is that it is the most lucrative sex to sell and prostitutes working in 'whore houses' as well as for escort agencies reported selling unprotected active and passive anal sex for this reason. R esearch on male sex workers is limited, and this phenomenon does not appear to have been documented before.

In sum, these data challenge the findings of a large body of research which suggests that most of the sex men have with other men is safer sex and that unsafe sex usually occurs within the context of 'regular' partnerships (e.g. H ickson, Davies \& H unt, 1992; Bloor, 1995; D avies et al., 1993). It is a matter of some urgency that research exploring the generalisability of results presented here is undertaken as they are based on a detailed knowledge of the majority of participants and the information has not been elicited by one-off structured or semi-structured interviews.

\section{HIV and gonorrhoea}

The analysis of data documenting the incidence of gonorrhoea supports the information and ideas presented above about the continuing practice of risky behaviour among those who are HIV + and HIV - as well as those who do not know their status. Eleven of the nineteen study participants reported that they had had gonorrhoea during the year of data collection; five of these participants were $\mathrm{HIV}+$, three were HIV - and three did not know their status.

These figures also draw attention to the need to differentiate between safe sex for HIV and safe sex for other sexually transmitted infections such as gonorrhoea. For instance, $\mathrm{F}$ ig. 5 demonstrates that everyone in this network is a maximum of five steps 
M. Parker, H. W ard and S. Day

away from someone who is reported to be HIV + . Oral and/or protected anal sex is reported in a large number of cases and since the majority of gonoccocal infections did not occur among men who are HIV + this draws attention to the fact that while oral and/or protected anal sex may be safe for HIV it is not safe for gonorrhoea. This should be borne in mind by those participating in endeavours to prevent the transmission of gonorrhoea as well as other sexually transmitted infections such as chlamydia.

\section{A ssessing the density of the network}

The majority of participants (twelve out of nineteen) reported having sex in public places such as cemeteries, toilets, parks, saunas and the 'backrooms' or 'darkrooms' of pubs and clubs. The amount of sociodemographic and biomedical information participants acquired about these contacts (either before or immediately after having had sex with them) ranged from nothing at all to details such as the contact's first name, approximate age, current occupation and HIV status.

W ithout exception participants who had had sexual contact with men in public places did not acquire any information about the contact's contacts. It is thus not possible to know whether any of these contacts have had sex with each other, whether any of the anonymous or casual contacts mentioned by one participant overlap with the contacts mentioned by other participants.

Interviews revealed, however, that all participants have favourite venues and that some participants go to the same venues as each other. F or example, participant 1 and participant 4 regularly go to the same sauna; and participants 5, 7 and 8 regularly go to the same clubs and have sex in the club's darkrooms. All these participants knew they had had sex with some of the same contacts at these venues but they also thought the proportion of shared contacts was relatively small. U nfortunately they could not put a number to this assessment and, from the point of view of understanding transmission, it is difficult to say how significant this is. The majority of anonymous contacts are reported to be safer sex contacts but this should be interpreted in the light of other information suggesting significant under-reporting on the incidence of unprotected anal sex.

\section{D iscussion}

A ssessing the methods used to identify networks

The network described in this paper is unusual. It is based upon interviews with a small number of participants and most of these interviews have not been restricted to discussions about the participant's current sexual activity. They have involved long and detailed discussions about a diverse range of social and economic factors which influence the participant's past and current life.

It has taken considerable time, patience and flexibility to develop this network. The time interval between meeting the first and second participants was 2 months and it took a further 4 months to make contact with the third participant. Subsequent participants were recruited relatively quickly and easily. This reflects the rapport and trust which had been established with the first few participants. 
The approach adopted in this study raises a number of questions which, to date, have not been addressed in the network literature. First, how, if at all, does the type of referral influence the type of information imparted by participants during an interview? Second, to what extent is information about the number and type of contacts influenced by the relationship established with the researcher and the frequency with which the participant is interviewed? Third, why is it hel pful to acquire multiple perspectives from linked inividuals? In view of the relatively small number of participants these questions are not addressed in an empirical way. Instead information and insights which emerged while developing the network are used in a qualitative way to address these questions.

W ith reference to the first question, it is striking that the three participants recruited through the clinic referral system tended to be 'economical with the truth' at a first meeting compared with the sixteen participants who were recruited through a friend or former partner away from the clinic. This became apparent over time and is indicated by a striking difference in the quality of information on the numbers of reported sexual contacts, the type of relationship with the contact, and the type of sex. A participant recruited through the clinic was more likely to mention more contacts with each and every visit and the quality of information about the participant and/or contacts altered with time. For example, participant 1 described having had four sexual contacts in the 3 months prior to being interviewed. One of these contacts was described as a boyfriend of 4 months' standing and he did not know anything about the number or type of sexual contacts he might have had prior to or during their relationship. During the third interview it was apparent that a great deal was known about his boyfriend's contacts, including the fact that he regularly sold sex and that he received more money for selling unprotected rather than protected anal sex. Similarly, participant 8 described having had three anonymous sexual contacts in a park and one on-going relationship with a man in the 3 months prior to attending the clinic. This participant is H IV + and during the fourth interview he spoke openly about the fact that he sold sex and had no idea how many commercial and non-commercial contacts he had had.

These difficulties are not surprising. It takes time to establish trust and rapport and a couple of interviews are rarely enough, especially if they take place in consulting rooms surrounded by posters conveying messages such as 'love carefully' and 'use a condom'.

By contrast, participants recruited to the study by sexual contacts or friends were open and forthcoming at a first meeting. Indeed, several participants prepared lists detailing their sexual contacts prior to this initial meeting-though they often did not say they had until the end of the first interview or the beginning of the second. Participants recruited in this way often volunteered information explaining why they were so willing to talk freely to a researcher that they had never met before about intimate aspects of their lives. W ithout exception, their reasons included the fact that their friend or contact had talked about the experience of being interviewed in a positive way and they trusted their judgement that the information imparted would be treated in confidence.

The second question is the extent to which information about the number and type of contacts is influenced by the relationship established with the researcher and the frequency with which the participant is interviewed. With the exception of one participant, everyone who was interviewed two or more times reported more sexual 
contacts, for a specified time period, at the second interview compared with the first interview. In addition, the majority of participants were much more forthcoming about the type of sex and type of relationship established with each of their contacts and, in several instances, generated useful information on the understanding of transmission. A gain, this is not surprising. The majoity of participants had at least ten contacts and it takes time to elicit sociodemographic, behavioural and biological information about each contact. Since participants were encouraged to talk in an unstructured way about their lives, and conversations were rarely restricted to a discussion of recent sexual activity, there was usually insufficient time to talk about each contact they had had over a 12-month period. M oreover, additional interviews enabled the participants to acquire a more detailed understanding of the rationale for the research as well as the attitudes of the researcher. Reliable information cannot be acquired without establishing a relationship that enables a participant to feel that they could entrust delicate and difficult information to the researcher.

The advantages of recruiting participants that are linked to each other (through friendship, or past or current sexual contacts) rather than recruiting through the anonymity of a clinic setting is that it is often much quicker to establish contact and trust (and consequently participants are much more forthcoming about sensitive and difficult information) as one already comes with a personal recommendation. For instance, one participant commented on the fact that a former contact had encouraged him to contribute to the study as he thought the researcher ( $\mathrm{M} P$ ) was easy to talk to and trustworthy.

The final question is whether it is helpful to acquire multiple perspectives from linked individuals, and this is important in view of the fact that identifying a network such as this is time-consuming and labour intensive. B riefly, there are four key ways in which networks developed in this way help to generate useful information. First, by developing two or more perspectives on one link it is possible to corroborate or refute reported sexual links and thereby assess the validity of the data collected. Thus participants who had had sex with other participants (e.g. participants 1 and 4, 1 and 5, 6 and 8 , and 2 and 3) all volunteered information enabling their sexual links with each other to be corroborated.

In addition, fourteen participants reported having indirect sexual links with other participants. F or example, participants 1 and 3 reported having had sex, at different times, with the same man; and participants 1 and 4 also reported having had sex at different times with the same individual. The link person in each case did not wish to participate so it was particularly useful to be able to corroborate these links. There were also seven reports of 'three-somes' and one report of group sex involving twelve men where the third, fourth, fifth person, etc, did not wish to participate.

A second advantage in acquiring multiple perspectives on linked individuals is that it helps to understand links which are not reported. For example, one participant reported that one of his recent sexual contacts was working as a male prostitute. This contact was subsequently interviewed but he did not say anything about selling sex. $\mathrm{He}$ did, however, mention that he could not talk as freely as he would wish as he was waiting to hear from the Home Office whether he would be granted permanent residence. $\mathrm{He}$ is A sian, HIV + and, in his own words, 'paranoid' about talking to people he does not know as he is never very sure whether they may or may not be 
associated with the Home Office. In view of the fact that it has been possible to corroborate most of the information imparted by participant 1 about his friends and sexual contacts, it was deemed appropriate to incorporate information about this contact's commercial contacts when constructing the network.

A third advantage to recording the different perspectives of linked individuals is that it helps to shed light on the context in which safe and unsafe sex occurs. For example, participant 4 spoke about having sex with a prostitute, participant 14 . The prostitute told participant 4 that he is HIV - and this participant mentioned the prostitute's reported status as a reason for having unprotected anal sex with him. Interviews with the prostitute, however, revealed that he was HIV + but that he tells clients he is HIV - as he always has protected anal sex and does not wish to frighten them unnecessarily. $\mathrm{He}$ is also afraid of losing custom if he reveals his H IV status.

A bove all, interviews with linked individuals generate a rich and detailed body of data enabling the complex nature of sexual links between participants to be identified and interpreted. The fact that it has been possible to validate all sexual links between participants is heartening but it does not help to answer the important question: what is the natureand extent of the links between the contacts of the participants? Is the network more inter-linked than has been indicated in this paper? If so, what are the implications for identyifying pathways of transmission and preventing the spread of HIV?

$\mathrm{N}$ etwork research as a tool for prevention

K lovdahl (1985); Trotter et al. (1995) and N eagius et al. (1994), among others, have suggested that network data can help to identify, implement and/or evaluate interventions designed to inhibit the spread of sexually transmitted infections such as HIV. The present study supports the idea that network data can help to identify individuals that may play a central role in transmitting infection as well as those at particular risk of acquiring infection.

F or instance, $\mathrm{Fig}$. 6 has been constructed from interviews with participants ' $a$ ' and ' $c$ '. It shows that participants ' $b$ ' and ' $c$ ' are at considerable risk for acquiring and transmitting infection from participant ' $a$ ' as it would only take a condom to split while ' $b$ ' was having anal sex with ' $a$ ', and for ' $c$ ' subsequently to have unprotected anal sex with ' $b$ ', for ' $c$ ' to then be in a position to infect at least two other men. Participant ' $c$ ' regularly attends a genito-urinary medicine clinic. A ssuming he is reasonably open about the number and type of sexual contacts that he has it is likely he would receive considerable advice about how to protect himself and his contacts from sexually transmitted infections. It is unlikely that participant ' $b$ 's' attendance would elicit the same response. T wo safer sex contacts would be innocuous in a busy L ondon clinic yet $\mathrm{F}$ ig. 6 demonstrates that he too is at risk of acquiring H IV infection. Indeed, he is one step away from H IV infection and two steps away from seven other men that are H IV +.

On the basis of Fig. 6 it could also be argued that network research could be used to help target individuals at risk of acquiring and transmitting HIV infection. A change in the behaviour of ' $b$ ' and ' $c$ ' could, after all, protect a considerable number of men. $\mathrm{H}$ owever, it is easy to be carried away by the logic of this kind of thinking. Information elicited during open-ended interviews during this research warns against such a hasty response. 


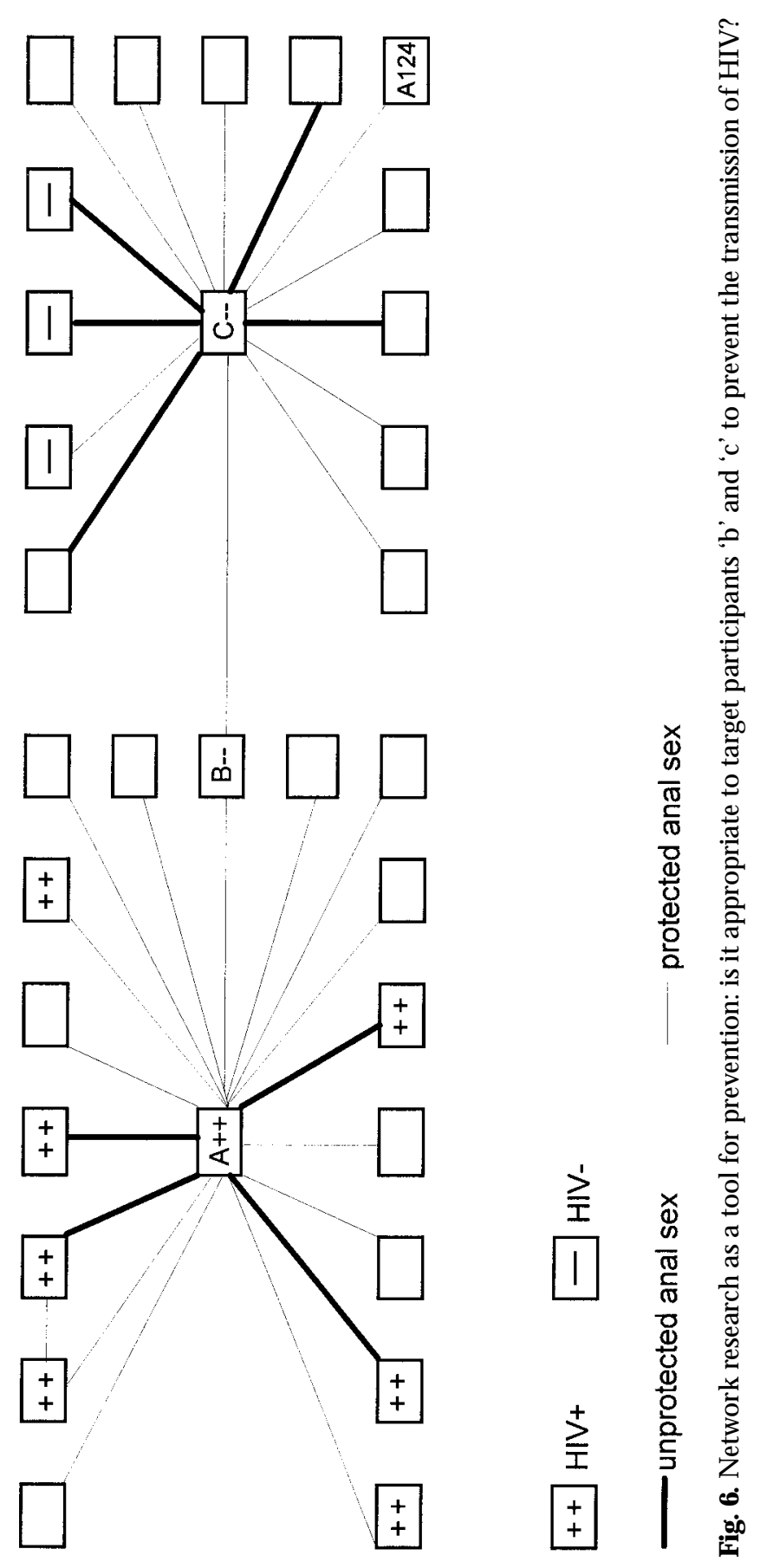


Indeed, it has drawn attention to the following inappropriate assumption informing work undertaken by so many health professionals: people who are HIV - (as well as people who do not know their status but think of themselves as HIV -) would prefer to remain HIV - . However, information emerging from this study suggests that while this may be the case for the majority of participants it is not necessarily the case for all participants. With reference to $\mathrm{F}$ ig. 6 , for instance, participant ' $c$ ' has a very detailed understanding of the transmission of HIV and the differential risks of acquiring HIV from different types of sexual activity. Healso spoke of his desire to be HIV + and this contributed to the fact that he often chose to have the riskiest kind of sex possible: unprotected passive anal sex. He attributed this behaviour to the fact that he found 'the potential endlessness of being alive very dreary and daunting'. Later on in the interview he said 'I'm not afraid of the idea of getting sick, or the experience of having a terminal illness or dying .... it would be another experience [pause] ... I've never really talked about this before but I've known about it'.

Other participants also drew attention to the fact that it cannot be assumed that those who are HIV - wish to remain HIV - . Indeed, several men in this study drew attention to the fact that many men, particularly young men, are envious of friends and associates who are HIV + . The reasons vary and include the following: men who are HIV + are perceived to have access to a wide range of resources including access to housing and special economic benefits such as disability allowances. These resources are usually acquired with the assistance of sympathetic and supportive staff and it is thus not surprising that men who are out of work, struggling to achieve a reasonable level of economic well-being and who express feelings of social marginality, depression and loneliness envy those who are H IV + . A s far as they are concerned sero-conversion would solve a number of immediate and important problems-for it is not as if they have any reason to suppose that their circumstances will significantly change in the future.

There is clearly a need for those engaged in the provision of health services to find ways to identify these individuals and, where possible, to provide sufficient support to enable them to alter their outlooks and behaviour. The combination of network research and unstructured, in-depth interviews has helped to draw attention to an issue which requires urgent attention by health professionals.

\section{C onclusions}

The sexual network data presented in this paper suggest that a diverse group of people are having sex with each other. Whatever the sociodemographic indicator (age, nationality, income, occupation) people are often choosing to have sex with people very different from themselves. The identification of this network has also drawn attention to the possibility of considerable on-going transmission of HIV in London. The majority of participants reported having had unsafe sex (unprotected anal and/or vaginal sex) between A ugust 1994 and J uly 1995; and this occurred in the context of a variety of relationships. This research has also helped to identify pathways of transmission between older and younger men, with male prostitutes often providing an important link between these two groups.

These data are based on a small number of linked individuals and it would be 
helpful to expand the network to further the understanding of mixing patterns between those who are HIV + and those who are HIV - . It would aso be useful to compare sociodemographic and biomedical information about the participants and their contacts with other data on men who have sex with other men. In particular, it would be useful to re-analyse data presented in the British $\mathrm{N}$ ational Survey of Sexual A ttitudes and Lifestyles (J ohnson et al., 1994; Wadsworth et al., 1996) in order to assess whether the participants in this network are representative of men who have sex with other men in L ondon.

$\mathrm{N}$ evertheless the ideas and information presented in this paper are based upon considerable knowledge of the study participants' sexual and social worlds. It has been elicited over a 24-month period and involved long, detailed, open-ended interviews as well as participant observation. This approach has demonstrated the merits of acquiring network data from linked individuals and it is a matter of some urgency that funding agencies support this type of research in the future.

\section{Acknowledgments}

M elissa Parker was able to carry out initial investigations into the transmission of HIV while working with Jon Weber, Sophie Day, Helen Ward and Azra Ghani on a research project funded by The Wellcome Trust on sexual networks and the transmission of gonorrhoea between 1993 and 1996. The Health Education A uthority subsequently funded M elissa Parker to complete the analysis of the data on HIV transmission. The authors would like to thank both organisations as well as Elizabeth Claydon, Una Goan and all the other staff at the Department of G enito-U rinary M edicine, Imperial College School of M edicine at St M ary's Hospital. A bove all, we are grateful to Tim Allen and all the study participants for talking so freely and supporting the study with such enthusiasm.

\section{R eferences}

A NDERSON, R. M., G UPTA, S. \& NG, W. (1990) The significance of sexual partner contact networks for the transmission dynamics of HIV. J . A cquired I mmune D efic. Syndr. 3, 417-429.

A NDERSON, R . M . \& M AY, R . M . (1992) Understanding the A ID S pandemic. Scient. Am. 85, 58-66.

A uerbach, D. M ., D arrow, W. W., J AFFe, H. W . \& Curran, J. W . (1984) Cluster of cases of the acquired immune deficiency syndrome. A m. J. M ed. 76, 487-492.

B LOOR, M . (1995) The Sociology of H IV T ransmission. Sage, London.

Coxon, A. P. M . (1995) N etworks and sex: the use of social networks as methods and substance in researching gay men's response to HIV and AIDS. In: Conceiving Sexuality: A pproaches to Sex Research in a Postmodern W orld. Edited by R. G. Parker \& J. H. G agnon. R outledge, London.

D avies, P. M ., H ickson, F. C. I., Weatherburn, P.\& Hunt, A. J. (1993) Sex, Gay M en and AIDS. F almer, L ondon.

G upta, S., A NDERson, R. M \& \& M AY, R. M . (1989) N etworks of sexual contacts: implications for the pattern of spread of HIV. AIDS, 3, 807-817.

H ARALDSDOTTIR, S., G UPTA, S. \& A NDERSON, R. M . (1992) Preliminary studies of sexual networks in a male homosexual community in Iceland. J. A cquired Immune D efic. Syndr. 5, 374-381. 
H ICKSON, F., D AVIES, P. \& HuNT, A. (1992) M aintenance of open gay relationships: some strategies for protection against HIV. AIDS Care, 4, 409-419.

J ohnson, A. M.J., W adsworth, J., Wellings, K.\& F IELD, J. (1994) Sexual Attitudes and L ifestyles. Blackwell Scientific, Oxford.

K LOVDaHL, A. S. (1985) Social networks and the spread of infectious diseases: the AIDS example. Social Sci. M ed. 21, 1203-1216.

K lovdahl, A. S., Potterat, J. J ., W oodhouse, D. E., M uth, D. E., M uth, S. Q. \& D arrow, W. W. (1994) Social networks and infectious disease: the Colorado Springs Study. Social Sci. $M$ ed. 38, 79-88.

L AUMANN, E. O. (1994) The Social Organisation of Sexuality: Sexual Practices in the U nited States. U niversity of Chicago Press, Chicago.

L aumann, E. O., G agnon, J. H., M ichaels, S., M ichael, R. T. \& Coleman, J. S. (1989) M onitoring the AIDS epidemic in the U nited States: a network approach. Science, 244, 1186- 1189

M ORRIS, M . (1994) D ata driven network models for the spread of infectious disease. In: E pidemic M odels: Their Structure and R elation to Data. Edited by D. M ollison. Cambridge U niversity Press, Cambridge.

N eagius, A ., F riedman, S. R ., Curtis, R ., D es J arlais, D . C., F urst, R. T., J ose, B., M ota, P., Stepherson, B., Sufian, M., W ARD, T. \& W Right, J. W. (1994) The relevance of drug injectors' social and risk networks for understanding and preventing HIV infection. Social Sci. $M$ ed. 38, 67-78.

PH L S A ID S C entre, C Ommunicable D isease Surveillance Centre, and Scottish Centre for I NFECTION AND E NVIRONMENTAL H EALTH (1995) Q uarterly Surveillance T ables N 0. 29.

Service, S. K. \& Blower, S. M. (1995) HIV transmission in sexual networks: an empirical analysis. Proc. R oy. Soc. 260, 237-244.

Trotter, R. T., R othenberg, R. B. \& Coyle, S. (1995) Drug abuse and HIV prevention research: expanding paradigms and network contributions to risk reduction. Connections, $\mathbf{1 8}$, 29-45.

W adsworth, J., H ickman, M ., J OHnson, A . M ., W ellings, K . \& F IELD, J . (1996) Geographic variation in sexual behaviour in Britain: implications for sexually transmitted disease epidemiology and sexual health promotion. AIDS, 10, 193-199.

W oodhouse, D. E., R othenberg, R. B., Potterat, J. J., D arrow, W. W., M uth, S. Q., K lovdahl, A. S., Zimmerman, H. P., R ogers, H. L., M aldonado, T. S., M UTH, J. B. \& REYNOLDS, J. U. (1994) M apping a social network of heterosexuals at high risk for HIV infection. AIDS, 8, 1331-1336. 